\title{
EXPERIMENTAL INVESTIGATIONS IN DISTRIBUTION PROCESS OF AMMONIA NITRATE BY ORKING BODY WITH INCLINED AXIS
}

\author{
Volodymyr Bulgakov ${ }^{1}$, Oleg Adamchuk ${ }^{2}$, Adolfs Rucins ${ }^{3}$, Simone Pascuzzi ${ }^{4}$ \\ ${ }^{1}$ National University of Life and Environmental Sciences of Ukraine, Ukraine; \\ ${ }^{2}$ Institute for Agricultural Engineering and Electrification, Ukraine; \\ ${ }^{3}$ Latvia University of Life Sciences and Technologies, Latvia; ${ }^{4}$ University of Bari Aldo Moro, Italy \\ adolfs.rucins@1lu.lv, simone.pascuzzi@uniba.it
}

\begin{abstract}
Improvement of machines for the application of mineral fertilisers is an urgent task both in terms of increasing productivity and uniform distribution across the working width. The disc centrifugal apparatus, as a rule, have a vertical axis of rotation. A working hypothesis has been suggested that the inclination of the axis of rotation in this case makes it possible to increase the spreading distance of fertilisers and thereby increase the working width of spreading. For experimental research a special stand was developed that allows to study distribution depending on the inclination of rotation axis of the fertiliser distribution disc, the disc rotation frequency and a number of other parameters. The investigations were carried out using ammonium nitrate. It was found that an increase in the rotational frequency of the disc of the new working body $500 \ldots 1100 \mathrm{rpm}$, and the angle of inclination of rotation axis to the horizontal plane $55 \ldots 95^{\circ}$ leads to a significant displacement of the entire mass of fertilisers from the spreading working body in the direction of their distribution. Better performance of the technological process of the fertiliser application by the range and uniformity of distribution takes place, when the angle of inclination of rotation axis of the disc of the new fertiliser distribution working body in the horizontal plane is within $55 \ldots 60^{\circ}$.
\end{abstract}

Keywords: ammonia nitrate, disc, distribution, uniformity.

\section{Introduction}

Mineral fertilisers are an important element of valid nutrition for plants and increasing the productivity of agricultural crops [1]. Biological farming is an environmentally friendly approach to agriculture; yet so far application of mineral fertilisers in agriculture in the countries where intensive technologies are used still is the basis for obtaining high yields. Therefore, the problem how to improve machines for fertiliser application is still relevant.

Introduction of mineral fertilisers is mainly affected by centrifugal distributors [2-3]. The other types of machines for applying mineral fertilisers so far have very limited use [4]. The efficiency of fertiliser applicators depends also on the working width or the spreading range of the fertiliser.

The issues of a possibility to increase the efficiency of centrifugal fertiliser spreaders have been studied by many authors [5-8]. However, a still little explored area is the study of the structures, in which the spreader disc is not in the horizontal plane but inclined in relation to the horizon. The performed theoretical studies show that by providing the direction of the transport velocity of the fertiliser element at an angle to the horizon, it will increase the spreading distance [9]. However, theoretically, it is very difficult to accurately calculate the distribution of mineral fertilisers along the spreading width, since the fertilisers, used now (even of the same chemical composition), have significant variations in the size of particles or granules, specific gravity and some variations in the design and technological indicators, and also there is a specific aerodynamics of the particle flight of the fertilisers in the air. The differences in the characteristics of the distribution of fertilisers also take place when using different types of fertilisers that differ in the parameters of the weight and shape of the granules [10-12].

The distribution of fertilisers after distribution from the disc along the width has a variable character in magnitude (at some distance from the disc a gradual decrease in the value of the mass of the distributed fertilisers is observed). Therefore, to ensure the required uniformity, a number of design solutions are used, as well as adjacent passes are carried out with overlap, which ensures double overlapping of the fertiliser mass and equalisation of the specific gravity of the fertilisers to be distributed along the working width. The distribution of fertilisers after distribution from the disc along the width has a variable character in magnitude (at some distance from the disc a gradual decrease in the value of the mass of the distributed fertilisers is observed). The uniform distribution of fertilizer across the working width is the most important quality indicator of the fertilizer spreader. 
The aim of the work is an experimental investigation of the introduction (distribution) of ammonium nitrate by centrifugal disc fertiliser working bodies depending on the rotation frequency and rotation axle inclination angle of the disc to the horizon.

\section{Materials and methods}

One of the important performance indicators of a fertilizer spreader is the uniformity of fertilizer distribution across the working width. The second important indicator is the spreading range - the greater the range, the greater the productivity of the technological operation can be.

We studied the experimental equipment with various fertilizers. This article reflects the results of studies of the uniformity of distribution of ammonium nitrate across the working width.

Various types of fertilisers, used in practice, have different physical and mechanical properties (specific gravity, size of the fertiliser granules, etc.). For this reason, to obtain a clear picture of the distribution of fertilisers along the working width of the machine, it is necessary to conduct research of different types of the fertilisers used. In this paper the results of the research of the distribution of ammonium nitrate are considered. The characteristics of the ammonium nitrate: the average moisture content $-0.17 \%$; the average value of the bulk density $-780 \mathrm{~kg} \cdot \mathrm{m}^{-3}$; the coefficient of friction on steel $-0.3 \ldots 0.6$; granulometric composition: $>1 \mathrm{~mm}-13.1 \% ; 1 \ldots 2 \mathrm{~mm}-83.5 \% ; 2 \ldots 3 \mathrm{~mm}-3.4 \%$.

A specially made equipment was used for experimental investigations (Fig. 1).

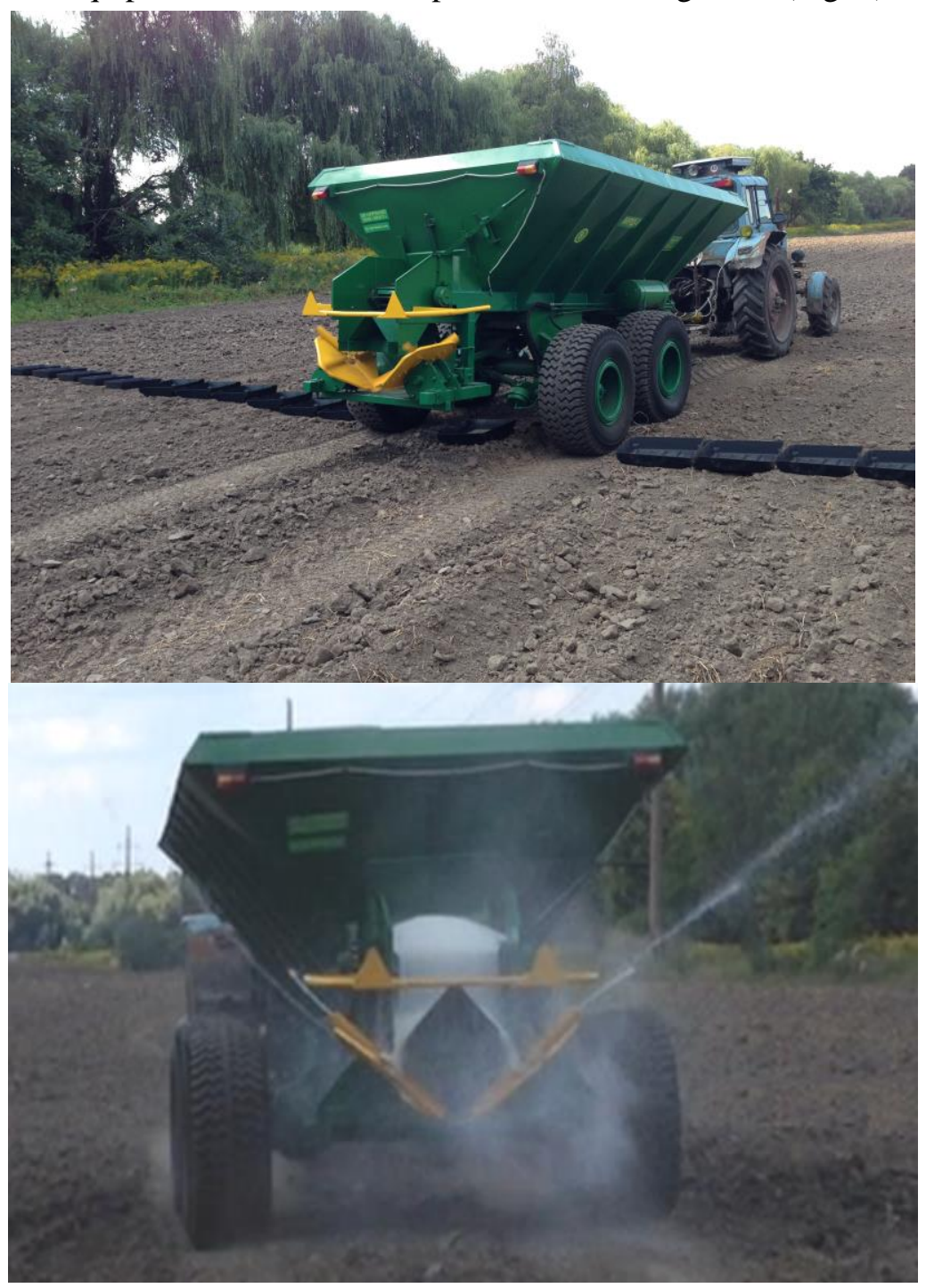

Fig. 1. Experimental equipment for study of the spread of ammonium nitrate by an inclined disk 
The experimental equipment made it possible to stepwise change the input parameters (the angle of the axle inclination and rotation frequency of the disc). The experimental equipment had the following main parameters: tractor speed $-2.85 \mathrm{~m} \cdot \mathrm{s}^{-1}$; spreading disc diameter $-650 \mathrm{~mm}$; distance of the fertiliser supply point from the centre of the disc $-150 \mathrm{~mm}$; distance from the throat of the sowing device to the surface of the spreading disc $-0.60 \mathrm{~m}$; disc distance from the ground $-0.42 \mathrm{~m}$; alimentation material flow $-0.45 \mathrm{~kg} \cdot \mathrm{s}^{-1}$; disk rotation frequency $500 \ldots 1100 \mathrm{rpm}$; angle of inclination of the disc axle to the horizontal $60 \ldots 90^{\circ}$. Experimental research was carried out on the installation (Fig. 1), created on the basis of a trailed spreader of granular mineral fertilisers, equipped with an experimental spreading device, with an ability to adjust the disc axle inclination within $60 \ldots 90^{\circ}$, and the disc rotation frequency within $500 \ldots 1100 \mathrm{rpm}$.

To study the impact of the disc rotation frequency and the angle of its installation upon the coefficient of the fertiliser distribution variation over the width of its effective spreading, a two-factor experiment was conducted with several levels of variation of the factors. At first, the applied dose of mineral fertilisers was determined, which was then used for each experiment in 3-fold repetition. This dose was calculated according to the formula:

$$
D^{\prime}=\frac{10 \bar{g}^{\prime}}{S}, \mathrm{~g} \cdot \mathrm{m}^{-2}
$$

where $\bar{g}^{\prime}$ - average mass (weight) of fertilisers in the container for an experiment, g;

$S$ - area of the container, $\mathrm{m}^{2}$.

Then deviation of the actual dose of fertilisation was calculated from the actual dose $\Delta D \%$, rounded to the first decimal sign, according to the formula:

$$
\Delta D=\frac{D_{z}-D_{f}}{D_{z}}, \mathrm{~kg} \cdot \mathrm{ha}^{-1}
$$

where $D_{z}$ - pre-set dose of mineral fertilisers, reduced to the working width of the application, $\mathrm{kg} \cdot \mathrm{ha}^{-1}$.

$D_{f}$ - actual application rate of mineral fertilisers at the real application width, $\mathrm{kg} \cdot \mathrm{ha}^{-1}$.

For uneven distribution of fertilisers over the total and the working width of fertilisation a coefficient of variation was chosen of the mass of fertilisers that fell into separate containers, installed along the total width in a continuous row, perpendicular to the direction of movement of the machine. Before the passage of the machine the containers with an internal size of $0.5 \times 0.5 \times 0.15 \mathrm{~m}$ (Fig. 2) or $1.00 \times 0.25 \times 0.15 \mathrm{~m}$ (Fig. 3) were arranged in three continuous transverse rows (Fig. 4). In each mode the experiment was conducted in three repetitions. Before the passage of the machine, containers with an internal size of $0.5 \times 0.5 \times 0.15 \mathrm{~m}$ (Fig. 2) or $1.00 \times 0.25 \times 0.15 \mathrm{~m}$ (Fig. 3) were placed in three continuous transverse rows (Fig. 4). In each mode, the experiment was carried out in three repetitions.

Dimensions in meters

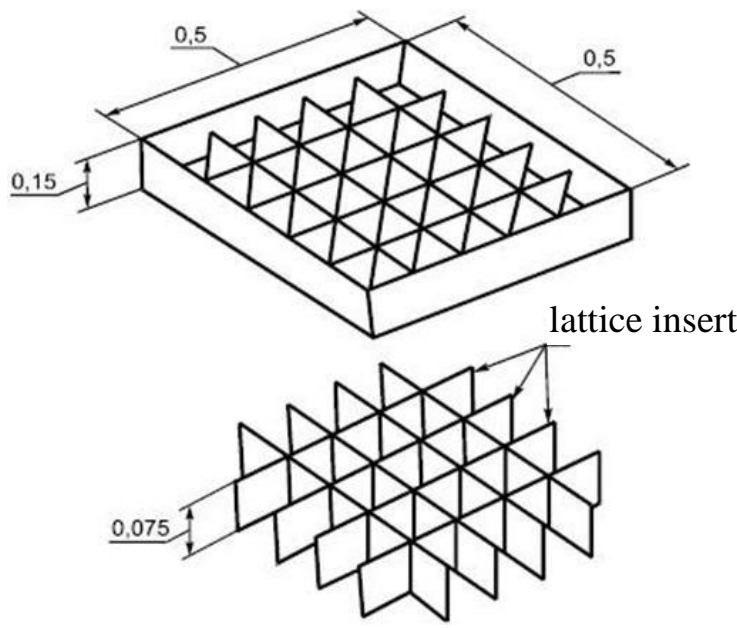

Fig. 2. Model container for collection of fertilizer, used in testing fertiliser applicators 


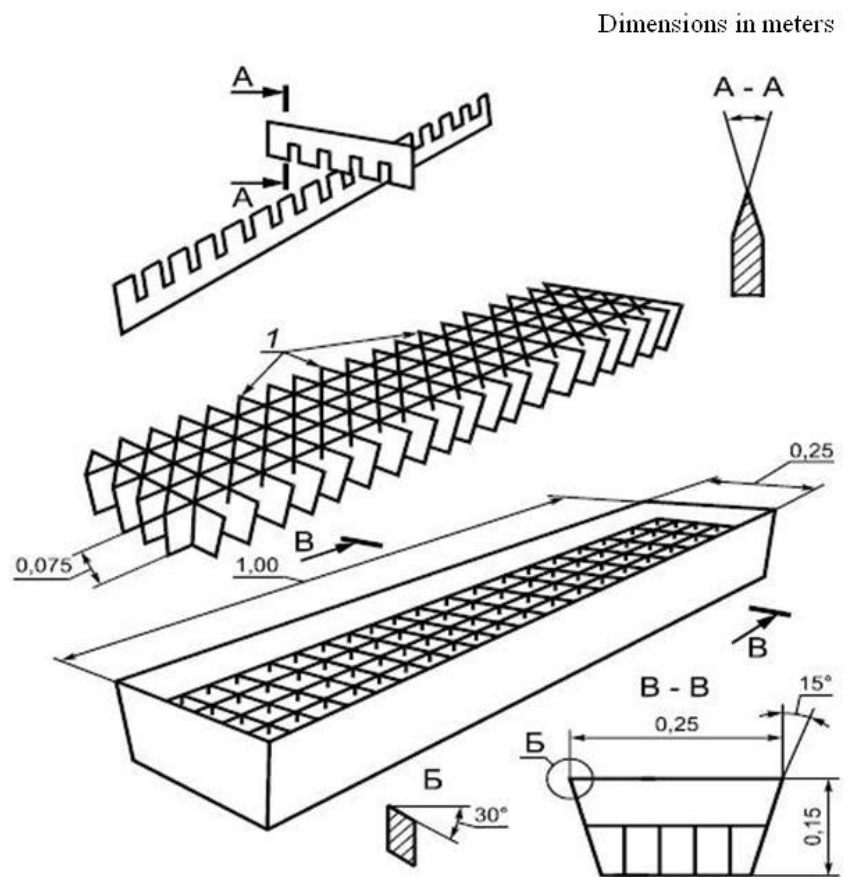

Fig. 3. Model container for collection of fertiliser, used in testing fertiliser applicators: 1 - lattice insert, dividing the container into 100 cells

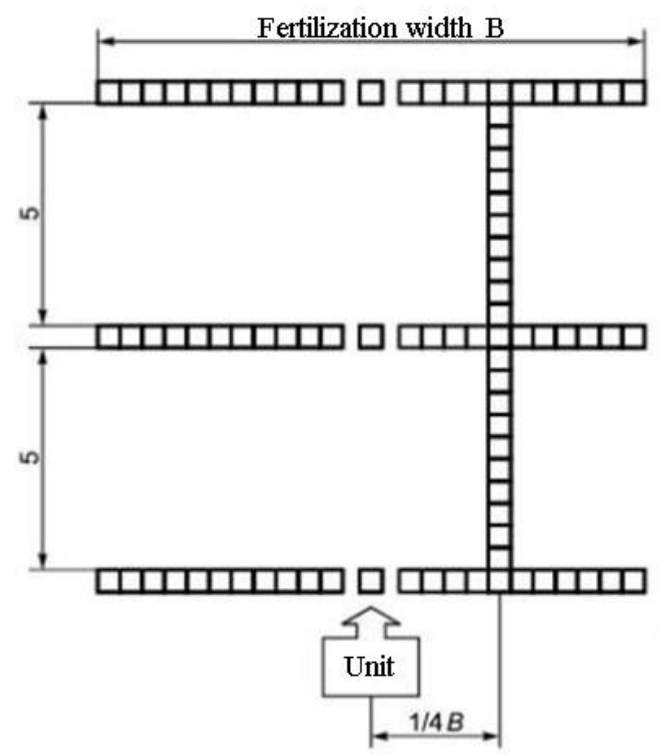

a)
Dimensions in meters

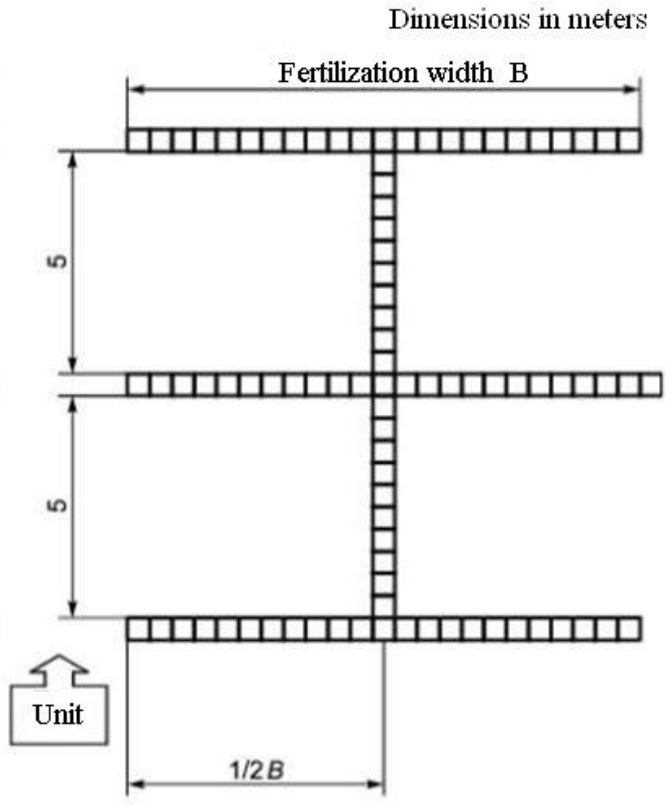

b)

Fig. 4. Scheme of arrangement of containers of one repetition when determining the quality indicators of the technological process: a - with symmetrical fertiliser application; $\mathrm{b}$ - with asymmetric fertilizer application

After the passage of the machine, the mineral fertilisers from each container were successively weighed with an error of $\pm 20 \mathrm{mg}$.

In the process of the experimental research basic provisions of the European Standard EN 13739-2 and the Standard GOST 28714-2007 were used [13-15].

There was threefold repetition of experiments for each investigated input parameter. The data obtained were processed by methods of mathematical statistics on a PC [16-18]. 


\section{Results and discussion}

In the experimental investigations of distribution of the ammonium nitrate material by the new fertiliser spreading working bodies with an inclined axis, developed by us, the effect upon the nature of the fertiliser distribution was considered according to:

- disc rotation frequency with its horizontal position and constant fertiliser delivery height to the disc surface;

- angle of inclination of the rotation axle of the distributing disc to the horizontal at a constant value of the disc rotation frequency and the height of the fertiliser delivery to the disc surface;

- height of the fertiliser delivery to the disc surface at a constant value of the disc rotation frequency and the rotation axle inclination angle of the disk to horizontal.

To study the effect of the disk speed and angle of its installation on the distribution variation coefficient of fertilizers over the width of its effective spreading, a two-factor experiment with several levels of variation of factors was implemented.

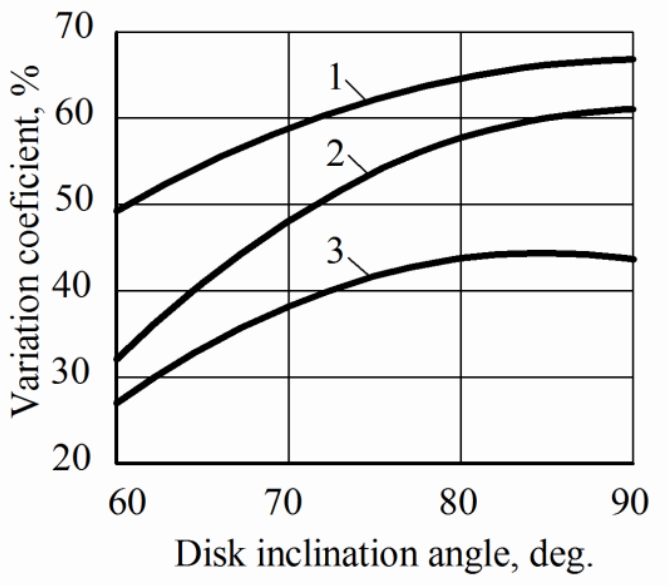

Fig. 5. Dependence of variation coefficient of ammonium nitrate granule distribution on disk axle inclination angle at disk rotation frequency: $1-600 \mathrm{rpm} ; 2-800 \mathrm{rpm} ; 3-1000 \mathrm{rpm}$

Reducing the unevenness of ammonium nitrate granule spreading can also be achieved by increasing the disk speed and reducing the angle of its installation. This is evidenced by experimental studies, the graphical dependences of which are shown in Fig. 6-7.

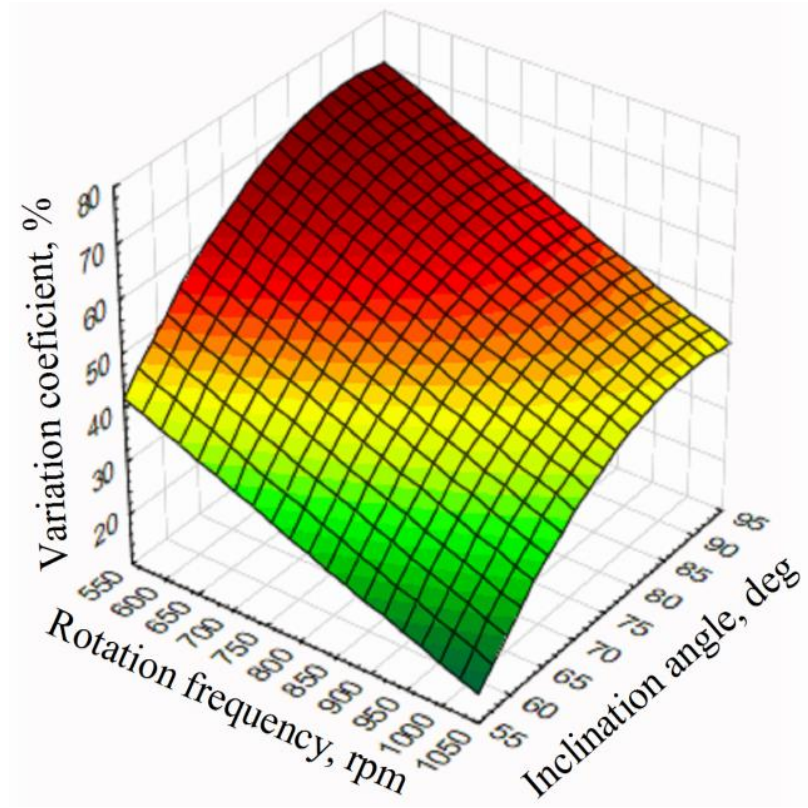

Fig. 6. Response surface of distribution variation coefficient dependence of ammonium nitrate granules on axle inclination angle and rotation frequency of the disk 
Analyzing the dependence in Fig. 6, it can be said that satisfactory variability of the process of spreading ammonium nitrate, less than $20 \%$, on the experimental installation can be achieved, when the disc axle inclination angle is less than $60^{\circ}$ and its rotation frequency is more than $1000 \mathrm{rpm}$.

Studying the two-dimensional section of Fig. 7, it can be argued that the disc axle inclination angle has a greater effect on fertilization uniformity (coefficient of variation) than the rotation frequency of the working bodies on the investigated range of factor change.

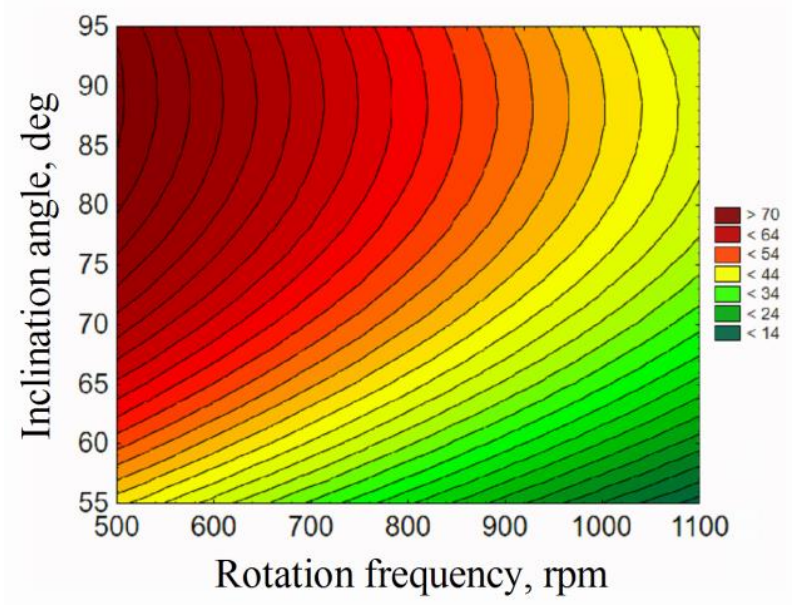

Fig. 7. Two-dimensional sections of response surface of the variation coefficient dependence of ammonium nitrate granule distribution upon axle inclination angle and rotation frequency

The regression equation of the influence of the disk rotation frequency $n$ and its axle inclination angle $\alpha$ on the variation coefficient $y$ of ammonium nitrate distribution will have the following form.

1. In natural values:

- in the form of a linear relationship

$$
y=42.8143-0.0545 n+0.657 \alpha ;
$$

- in the form of polynomial dependence

$$
y=-101.4-0.0574 n+4.6034 \alpha-0.0256 \alpha^{2} .
$$

2. In coded values:

- in the form of a linear relationship

$$
y=49.6395-10.9067 X_{1}+6.8052 X_{2} ;
$$

- in the form of polynomial dependence

$$
y=48.3022-10.92 X_{1}+7.8478 X_{2}+0.2467 X_{1}^{2}+0.9122 X_{2}^{2}-0.04 X_{1} X_{2} .
$$

where $X_{1}$ - rotational frequency of the disk in a coded value, rpm;

$X_{2}-$ angle of axle inclination of the disc in coded value, deg.

The spreading uniformity of ammonium nitrate granules will be most affected by the rotation frequency, and effective distribution of fertilizer granules on the field surface will be achieved at a disk speed of $1000 \ldots 1100 \mathrm{rpm}$. and the axle inclination angle of the disk $-55 \ldots 60^{\circ}$.

In general, according to the results of experimental studies, it should be noted that the value of granule distribution uniformity of all studied fertilizers corresponds to normal distribution law.

\section{Conclusions}

1. The response surface of dependence of the coefficient of variation of the distribution of ammonium nitrate granules upon the angle of axle inclination and the rotation frequency of the disc was determined. 
2. By analysis of the experimental studies of the speeding tool a tendency was established towards a decrease in uneven spreading of the ammonium nitrate granules with an increase in the rotational speed of the disc and a decrease in the angle of its installation.

3. Satisfactory distribution of fertilisers by the experimental tool with surface application of ammonium nitrate can be achieved under the following operating modes for ammonium nitrate the disc rotation frequency $850 \ldots 1100 \mathrm{rpm}$, the axle inclination angle of disk $55 \ldots 65^{\circ}$.

\section{References}

[1] Adamovics A., Platace R., Gulbe I., Ivanovs S. The content of carbon and hydrogen in grass biomass and its influence on heating value. Engineering for Rural Development, 17, 2018, pp. $1277-1281$

[2] Kobets A.S., Naumenko M.M., Ponomarenko N.O., Kharytonov M.M., Velychko O.P., Yaropud V.M. Design substantiation of the three-tier centrifugal type mineral fertilizers spreader. INMATEH - Agricultural Engineering, Vol. 53, Issue 3, 2017, pp. 13-20

[3] Adamchuk V.V. Investigation of the general case of dispersal of mineral fertilizers by a centrifugal dispersing body. Bulletin of Agrarian Science. No. 12, 2003, pp. 51-57

[4] Przywara A. The impact of structural and operational parameters of the centrifugal disc spreader on the spatial distribution of fertilizer. Agric. Agric. Sci. Procedia, 7, 2015. pp. 215-222.

[5] Bulgakov V., Adamchuk O., Ivanovs S., Nowak J. Research of descent of mineral fertiliser particle from disc inclined at angle to horizon. Engineering for Rural Development, Vol. 19, 2020, pp.390398

[6] Przywara A., Santoro F., Kraszkiewicz A., Pecyna A., Pascuzzi S. Experimental study of disc fertilizer spreader performance. Agriculture (Switzerland), Vol. 10 (10), 2020, Art. 467, pp.1-11

[7] Villette, S., Cointault, F., Zwaenepoel, P., Chopinet, B., Paindavoine, M. Velocity measurement using motion blurred images to improve the quality of fertiliser spreading in agriculture. Proceedings of SPIE-The International Society for Optical Engineering, Vol.6356, 2007, Art. 63560I.

[8] Koko J., Virin T. Optimization of a fertilizer spreading process Mathematics and Computers in Simulation, 79 (10), 2009, pp. 3099-3109.

[9] Bulgakov V., Adamchuk O., Ivanovs S. Theoretical investigations of mineral fertiliser distribution by means of an inclined centrifugal tool. Proceeding of $6^{\text {th }}$ International Conference on Trends in Agricultural Engineering - Part 1, 2016, pp.109-116.

[10] Hofstee J.W., Huisman W. Handling and spreading of fertilizers: Part 1, Physical properties of fertilizer in relation to particle motion. J. Agric. Eng. Res, 62, 1990, pp. 9-24.

[11] Dintwa E., Tijskens E., Olieslagers R., De Baerdemaeker J., Ramon H. Calibration of a spinning disc spreader simulation model for accurate site-specific fertiliser application. Biosystems Engineering, 88 (1), 2004,. pp. 49-62,

[12] Biocca M.,Gallo P., Menesatti P. Aerodynamic properties of six organo-mineral fertiliser particles. Journal of Agricultural Engineering, Vol. 44, 2013, Art. e83, pp. 411-414

[13] European Standard EN 13739-2:2011 Agricultural Machinery - Solid Fertilizer Broadcasters and Full Width Distributors - Environmental Protection - Part 2: Test Methods. CEN: Bruxselles, 2011.

[14] Standard GOST 28714-2007 Машины для внесения твердых минеральных удобрений. Методы испытаний (Machines for applying solid mineral fertilisers. The test methods). Moscow, 2007. (In Russian)

[15] Standard GOST 20915-2011. Методы определения условий испытаний. Испытания сельскохозяйственной техники (Standard 20915-2011. Testing of agricultural tractors and machines. Procedure for determination of test conditions), Moscow, 2011, 47 p. (In Russian)

[16] Burdo O., Bandura V., Kolianovska L., Dukulis I. Experimental research of oil extraction from canola by using microwave technology. Engineering for Rural Development, Volume 16, 2017, pp. 296-302

[17] Ivanovs S., Adamovics A., Rucins A. Investigation of the technological spring harvesting variants of the industrial hemp stalk mass. Agronomy Research. Volume 13, Issue 1, 2015, pp.73-82

[18] Доспехов Б. Методология полевого опыта (Methodology of field experiments). 2012, Moscow, $352 \mathrm{p}$. 